\title{
Editorial
}

\section{Framing the gap: Contact [and] improvisation}

\section{Misri Dey and Malaika Sarco-Thomas}

This special issue of The Journal of Dance and Somatic Practices focuses on contact [and] improvisation praxis. As a movement proposition, Contact Improvisation (CI) has done much to influence developments in the field of dance and somatic practices since its inception in the early 1970s. In the nearly 40 years of Contact Quarterly's circulation as a vibrant publishing platform and newsletter for dance, improvisation and CI practices (since the first Contact Newsletter in 1975), and despite a rise in postgraduate and doctoral research into $\mathrm{CI}$, there has not yet been a peer-reviewed academic journal issue dedicated to a discussion of practices and theories emerging from CI.

For the editors, this gap seemed an important one to name, and the invitation to edit this issue emerged following organization of two conferences as part of Contact Festival Dartington 2013 and 2014 at Falmouth University, UK, both of which focused on discussing CI practices. The 2013 conference, Political Ecologies in Contact: Articulating Improvisation Practices, 1 invited practitioner and academic responses to the notion of articulating what CI is, and in 2014 Contact Improvisation for Critical Response 2 asked contributors to consider how CI practices might operate as platforms for critical exchange. The conference featured different formats for dialoguing, questioning and feedback on presentations, including a moving, talking 'tête-à-tête' score that proposed a conversational perambulation in the studio to bring duets and then larger constellations of 
delegates together into conversations as a way of teasing out and developing research questions from the day. Reflections included surprise at the potential of CI methodologies and metaphors to be useful in research in the social and natural sciences, as well as within dance studies.

Following these conferences, the extremely high response rate to the call for papers for this issue of JDSP also indicates that CI praxis as a lens for academic research is a rich and developing field. Next year's annual European Contact Improvisation Teacher Exchange (ECITE), an annual forum for discussion and sharing of CI pedagogy in Europe, will focus on 'Contact Improvisation \& Research: Emerging Collaborations' as a starting point for the gathering taking place at Université d'Orléans, France, in July 2015. Event flyers invite researchers from all disciplines to participate in shaping the event (www.ecite.org). We hope that, in support of these and other recent developments in movement research, the collection of articles presented here begins to map and offer routes towards exploration of a few trajectories within this growing field.

\section{What does the '[and]' do in 'contact [and] improvisation'?}

The term ' $\mathrm{CI}$ ' is used to identify a practice arising from an original movement score initiated by choreographer Steve Paxton and a group of co-investigators in the 1970s:

The improvised dance form is based on the communication between two moving bodies that are in physical contact and their combined relationship to the physical 
laws that govern their motion - gravity, momentum, inertia. (Paxton et al. 1979 cited in Anon. n.d.)

The score has also been articulated as 'a physical dialogue' in which 'dancers focus on the physical sensations of touching, leaning, supporting, counterbalancing, and falling with other people' (Novack 1990: 8). While written definitions about the specificity of the intention behind the score vary, communication and dialogue feature as key aspects for many of the definitions. For example, in 1980 choreographer Stephen Petronio wrote that 'in CI we fall alone and together [...] partners ride weight along common paths of momentum' (Anon. 1982: 59, emphasis added), highlighting the 'and-ness' of the form as a solo and duet endeavour. A 2009 workshop announcement by Ray Chung bypasses reference to communication in favour of introducing CI as 'an open-ended exploration of the kinaesthetic possibilities of bodies moving through contact' (Anon. n.d.), where contact is introduced as something that is 'moved through' rather than something that bodies 'are in'. Within this issue of The Journal of Dance and Somatic Practices, we propose to look at what moves through the spaces between the basic acts that compose CI by including 'and' as an invitation to critically recognize the relationship between both acts.

The square brackets indicate an editorial insertion, in which a conjunction is added to make the tradition of 'CI' as a movement form more porous. Here, '[and]' opens up space for 'change through exchange' (Deitch-Dey 1998) between the two terms, and gives value to the gap there, in the way that CI practice attends to the space between two 
movers. This '[and]' points also to the third space in CI, the rolling point of contact, again variously depicted: Paxton in 1975, 'cooperation becomes the subject' (1975: 41), continued by Williams in 1996:

the third party in the dance [is] the point of con()tact: that fugitive and always temporary centre and edge common to both yet outside both, a 'blind spot' throughin-with-around-for-and-by which the two bodies orient their play. (1996: 25, original emphasis)

Williams' round brackets hold the space between the aspects of 'with-ness' in 'con' and touch in 'tact'. They also suggest a space, that, when analysed in the light of the writing of theatre maker and educational theorist Paulo Freire, is a site of emergent, liberatory potential:

As well as creating the possibility of exchange in the moment to moment contact dance, the point of contact can be described as being a primary site of 'untested feasibility' (Freire 1996:9) [where] the 'untested feasible' is something which exists but has not yet been realised'. (Deitch-Dey 1998: 56)

We posit '[and]' as a similar space of diverse possibility, also reminiscent of 'the gap' that Nancy Stark Smith names within the Underscore: in 'the gap', a dancer finds himself between two known experiences, creating a space of intelligent 'not-knowing' from which to act (2012). 
If, as cultural theorist Lawrence Grossberg proposes, identity is an action, articulated through practices of choosing alignments, rather than a subjectivity that is essential and fixed (Grossberg in Hall and Du Gay 1996: 87), then for CI, articulating the practices that operate within the expanded, conjoined fields of 'contact' (broadly, touch, communication, relationship) and 'improvisation' (broadly, responsive performance, instant composition and attentive but unplanned responses to a changing situation) can diversify the canon of work identified with this questioning form. Simultaneously, CI and related kinaesthetic research into responsive movement propositions are evolving through practice. Through multiple dancing acts, these practices offer further perspectives on how improvisers 'move through' contact.

\section{In this issue}

This issue features articles responding to an invitation to articulate such practices and includes a number of artist-led perspectives. Themes emerging include the following: the notion of 'threeness' in CI; CI principles as explored through performance-making and creative work; the ethics of relating through touch in improvisation; and the temporal dynamics of CI practice in teaching and training. CI performance principles within creative work are articulated through practice as research findings in articles by Angharod Harrop, Cheryl Pallant, Marie Fitzpatrick and Vahri McKenzie; within this group Fitzpatrick and Pallant include discussions on 'threeness' or 'a third entity' as crucial to their creative processes. Ethics of relating through touch, and ethics of alterity, are addressed in articles by Ruth Pethybridge, Malaika Sarco-Thomas and Katie 
Dymoke. Finally, the temporal dynamics of CI are particularly explored through three articles that focus on teaching and training of CI: those of Elsa Urmston and James Hewison, Stephen Smith, and Nita Little.

In her article 'I can feel his heart beating through the sole of my foot: Reflections on improvisation from a dancer finding her feet', Angharod Harrop shares her own discoveries as a student of improvisation performance, narrating conversations and performance moments across five years of study and interaction with Julyen Hamilton, Kirstie Simson and Rosemary Lee. Her writing reflects and captures the intimacy of experiencing improvisation as a state of discovery, while conveying the sense of excitement that this state of curious uncertainty (consider for instance the delicious tipping point of an upside-down balance) can bring to an expansive, lifelong project of research, rehearsal and performance of movement and stillness.

In 'Beyond skin boundaries in Contact Improvisation and poetry', Cheryl Pallant draws on the notion of CI as the 'third entity' in a dance between two people to delineate a CI score for writing poetry. Pallant invites the presence of unexpected sound and movement as a virtual partner and an Other whom she responds to in a flow of writing. Her contribution includes poetry arising from this 'embodied, kinetic technique' of bringing interruptions into improvisational writing. The article offers a textual exploration of the idea that CI practice can articulate the productive space of encountering otherness. This notion of $\mathrm{CI}$ as a visceral and dialogic response to otherness is addressed in several articles within the issue. 
In 'The threeness of three ones', Marie Fitzpatrick explores threeness using aspects of contact in a 30-minute performance score carried out on a platform block in a gallery space. The three dancers carry out specific performance tasks - for example, the action and exploration of taking off a jumper, complexified by their bodies being stacked one on top of the other. Their individual actions are changed through negotiating each other's bodies, which interrupt and reconfigure this pedestrian action. Successful negotiation in this context is not just aesthetically necessary: what is at stake is the dancers' physical safety, crowded onto the small platform, publically on show as a moving artwork, always at risk of falling. A concern for the safety of oneself and of others inscribes ethical practices into the work, a negotiation where people's physical well-being is, literally, 'on the line'. As well as creating co-dependency in the dancers, Fitzpatrick further proposes that an audience's engagement is triggered by this performed risk, a kinaesthetic empathy whereby their physical intelligence senses, imagines and somatizes some aspect of this jeopardy and subsequent negotiation.

In ‘Underscore alchemy’, Vahri McKenzie transmutes Nancy Stark Smith’s collaborative improvisation model, 'the underscore', into workshop material, which can be understood by arts undergraduates from disciplines other than dance. She describes and analyses a series of research workshops, facilitated by two CI practitioners, in which they offer stages of the underscore, physical working - from preparation - walking, standing still, exploring embodiment and space - to 'grazing' and engaging in a more open improvised 
score. These experiences are then explored and transposed into visual representations and analysed by McKenzie. She proposes that creative practice of the underscore is relevant to these students in offering a model of practice-led-research, which practises heuristic knowledge acquisition (learning through doing), prioritizing sensory intelligence and requiring an overt positioning of the self in relation to the work. She suggests that the kinds of embodied, contact and improvised experiences in the workshops translated into their work with visual and sonic materials. This included the use of coincidence and influence, collaborative working, and open, non-pre-emptive curiosity, which was both challenging and informative for students used to solo practices and less used to prioritizing physicality within a creative process. Embodied working becomes performance art - the body in action, engaged; purposeful, conscious movement becomes performance. McKenzie's work is a clear example of how principles, characteristic of CI, are translated, applied and extended into other contexts of art practice - in this case, visual arts. Both Malaika Sarco-Thomas and Stephen Smith also reveal this interest Sarco-Thomas with words and Smith in sonic practice.

In 'Relative proximity', Ruth Pethybridge explores the different kinds of communication enabled in using this dance form across generations of people. She includes three case studies: ongoing exploratory CI dance practice between herself and her baby and toddler Romilly, performances by mother and adult daughter and by a son and father who has Parkinson's disease. 
She centralizes phenomenological intelligence as activated in CI, exploring the kinds of communication enabled by it and the ethics it reaches towards embodying. Within the common characterization of $\mathrm{CI}$ as based on weight exchange, improvisation, ease, play and qualities of listening, she locates play and listening as being particularly relevant to dance practice across generations of people. Drawing on Levinas, she discusses how CI triggers ethical issues of physical vulnerability, power, in the face-to-face dance encounter. As well as exploring the more common characteristics of ease, exchange, spontaneity, developmental movement and play that CI instigates, Pethybridge also herself reaches towards an articulation of the non- 'cooperative' aspects of CI - the anger, 'violence', manipulation and tension that can arise in dancing. She draws on Derrida and Massumi to suggest that individuality, disagreement and shared uncertainty within the duet dance is desirable, possible and political in allowing difference: a 'being singular plural' (Nancy 2000). Ethics in this context refers to an open, present, embodied conception of others beyond set identifiers of age, ability or gender. It also refers to the relational aspect of CI, as a primarily duet and group dance practice (although many would argue that solo CI can also be explored).

Pethybridge argues that CI creates embodied ethical relationships and defines these ethics as rooted in relational practice: the 'I' with the 'you' where neither has to become the other but can explore, challenge, provoke and experience another moving body without needing to become them, or change them. CI, as a physical dance practice, allows for singular plural coexistence, including dances of different ages, abilities, strength and desire. Her work is refreshing in acknowledging the tension, violence, anger and fear 
involved in collaborative or cooperative working, as well as consensual agreement. Paraphrased simply, this includes communicating 'no' as well as 'yes' and the physical consequences of this. In theatre, collaborative practice can also involve such tension, disagreement, conflict and collision of messy ideas, and the fallout from this is the work. This is much needed in a discussion of CI that aims to address politics or ethics allowing difference and disagreement as particular kinds of 'flow' as much as saying yes, and moving with someone.

Malaika Sarco-Thomas' article 'touch + talk: ecologies of questioning in Contact Improvisation' focuses the discussion on CI as a physical research practice, its primary method a process of 'questioning' that CI instigates in relation to another person, space and environment, with her facilitated score called touch + talk. She suggests that CI, through its particular training and practice rooted in dialogic practice, can engage with Guattarian 'ecosophy': an 'ethico-aesthetic' approach to activating social and individual practices to address the 'increasing deterioration of human relations with the socius, the psyche and "nature"' (Guattari 2000: 41). 'Dialogue' is particularly relevant to her work, as in other essays in this issue, specifically as an engagement between the 'di' from Ancient Greek $\delta_{F} l \gamma \alpha$ meaning 'through, during, across, by' and 'logue' - $\lambda o \gamma o \varsigma-$ meaning 'word, speech, discourse' - that is, 'through discourse'. In this case the kinds of physical discourses that unfold in $\mathrm{CI}$ emphasize listening, attentiveness and responsiveness as much as doing, initiating or performing. Sarco-Thomas explores what occurs when the physical questioning process is further verbally articulated, done while practitioners dance $\mathrm{CI}$. Dance practitioners have long had to defend and promote the 
value of somatic knowledge, physical discourse and non-verbal intelligence arising from dance, without necessarily the need to verbalize it; so Sarco-Thomas negotiates tricky terrain here - provoking the question as to what is re-captured by language - in this case, in the simultaneous movement and verbal practice.

Questioning as a radical method includes questioning the self in relation to another person, and this self-conscious critique is, for Levinas and later for American pragmatic Richard Sennett (2008), a radical, creative, ethical process. At the heart of this work is the idea that the ability to engage in self-interrogation with another and to be an individual in relation to others is ethical practice, which engages politics around agency, power, the individual and the group. The meeting in CI therefore incorporates these questions about power and agency, self and other, and, importantly, these are witnessed by others in a public practice forum. Sarco-Thomas acknowledges that talking while dancing interrupts both physical and verbal articulations and suggests that these interruptions, gaps and challenges reveal the CI workings as much as smooth, flowing dance work. This echoes Hans Thies Lehmann's notion of avant-garde theatre practice as being as much about disrupting known working or modes of intelligibility as about creating new paradigms, and resonates with post-structuralist performance study discourses that focus on the creative potential of failure, hesitation and deconstruction as performance material, as much as virtuosic performance.

Katy Dymoke examines contact as touch through the lens of her work as a professional using CI, Body Mind Centring ${ }^{\circledR}$ and Dance Movement Psychotherapy practices in her 
article 'Contact Improvisation: The non-eroticised touch in an "art-sport"'. In accounts from twenty years of work with Touchdown Dance and other groups, she acknowledges some of the challenges that non-eroticized touch poses to practitioners, and through her observations offers different possibilities for recognizing and constructing touch as an 'inquisitive' rather than only receptive sense, and operating among all the senses as a permeable membrane through which the outer world sees itself through the particularity of each body. For Dymoke, the senses and touch act 'as a permeable field of interaction with self and other' and CI work necessarily highlights some of the cultural and social consequences of touch deprivation in marginalized individuals. Through documentation and analysis of her work with blind and partially sighted individuals, Dymoke shows how facilitated explorations of improvisational touch and contact can provide a sense of 'a way to move in the world freely', in the words of a deaf blind Touchdown performer, creating an important space for touch to be used as a creative rather than purely functional interaction with one's environment. Describing CI practice as 'looking from in to out rather than looking at', Dymoke also suggests that CI's involvement of all the senses within the spectrum from 'in to out' awakens the 'sensuous physical self', triggering shifts in self-perception and providing opportunities to reconstruct our social selves through physical dialogue.

Elsa Urmston and James Hewison touch on the emergence of a third entity in the CI dance when describing an event 'which appears to take on a life of its own and becomes knowingly pleasurable', a moment that is characterized by a 'merging of action and awareness' in flow theory. In their article 'Risk and flow in Contact Improvisation: 
Pleasure, play and presence', they suggest that engaged learning and risk-taking in CI can flourish best 'when the boundaries of dancing and playing are blurred' in a nonhierarchical learning environment that supports and recognizes discoveries made by each member of the group. Urmston and Hewison apply Csikszentmihalyi's flow theory to an analysis of teaching CI in higher education contexts, asking how risk-taking can be both enabled and taught within institutional contexts. Through two meticulously documented case studies they research how experiences of 'flow' can be recognized by learners of CI in two distinct workshop settings. Their focus group interviews indicate that workshops that function 'as a meeting point for exploring without a preconceived outcome' can create a non-judgemental environment for discovery that is more conducive to group flow, enjoyment and a sense of discovery. Such a meeting point echoes the metaphor of the point of contact as a space of pure, not-predetermined, potential.

Stephen Smith offers vibrant performance writing, and he carries out a leap into the sonic realm, exploring the synaesthetic potential for making contact, meeting others' sound making by paying attention to their polymorphous rhythms and tones of their own language movement and speech utterances - humans, animals, all. In 'A pedagogy of vital contact' he is particularly engaged with how CI transposes to educational contexts. He explores the synaesthetic physicality and musicality of speech utterances, of languages and 'rhythmicities' of tongue usage, and discusses how thinking about CI can be transposed as a multilingual connection with another. He relates $\mathrm{CI}$ to pedagogical practices that engage with relationality and vital aliveness to the moment in time, a duration or enduring with another, in a sensory, open and aware present. He draws on 
Alfonso Lingis' writing about movement as not necessarily being end-goal and purposive, but also as continuous being-in-motion, at times wonderfully aimless. He riffs on the notion of the durational 'accent', expanded into a definition of the characteristics of CI and across other disciplines that use tact, durational kinds of tempo and exchange. 'Vital contact' creates a useful kind of 'agogy' - facilitating and provoking mutual learning, including familiar evocations of $\mathrm{CI}$ as including awareness of the present moment, 'withness', reaching towards others, enjoying the uniqueness of the individual: all resonant in evocations of this practice throughout this issue. Smith argues that in these pedagogic principles we can connect with a dynamic matrix - 'a motility field' - through teaching that allows moments of ungovernable anarchic 'becoming' before entering the macro-slap structures of institutional regulation. For Smith, the CI practice space allows some romping to occur.

Nita Little's article 'Restructuring the self-sensing: Attentional training in Contact Improvisation', articulates the nuances of physical communion that can take place in advanced CI dancing. In doing so she charts a radical proposal for valuing attention training in CI practice. Using her experience as a teacher she opens up the possibility of 'a politics of attention' that can become more refined through exercise and experience. Detailing how a mover's sense of self can shift through a change in values when 'we no longer elevate stability over uncertainty, power over movement, or objects over their relations' Little posits attention as a living dynamic, which, in the words of Teresa Brennan, 'is a biological force that encourages well-being' (2004: 34). Drawing on, and somaticizing, Erin Manning's work that theorizes the moving body as a virtuality that is 
material, and Karen Barad's writing on theoretical physics in which touch, as 'intraacting' attention, changes things we observe, Little proposes that sensing is performative, and 'it thus matters how things are sensed'. Her thesis extends towards ecology as she writes, 'the virtual is the self that influences/is influencing/will influence the past, the future, and concurrent motion or events, all of which are in a relational ecology'.

Little's use of 'ecology' as sensitivity to interrelationships strengthens definitions proposed in Sarco-Thomas' $2010 \mathrm{Ph} . \mathrm{D}$. thesis 'Twig dances: Improvisation performance as ecological practice', where she posits that for dance improvisation practices the body is the medium, and awareness, perception or attention is the currency:

As I use the term, 'ecology' can introduce radically sensitized propositions for relating through active dialogue, generating practices which investigate relationships between people and ideas, people and environments, people and people, and people and objects on multiple levels. (Sarco-Thomas 2010: 2).

Little also introduces the term 'response-ability' within her article, proposing attentional training in $\mathrm{CI}$ as a readiness to respond to constantly changing situations within movement. The term resonates with the idea of ecological stewardship through improvisation put forward in 'Twig dances', where 'response-ability' is located in terms of a Darwinian readiness to encounter and negotiate changing physical, social and political circumstances and is realized through the playfulness, strength and sensitivity of 
dancing encounters within the studio (Sarco-Thomas 2010: 169). For Little as well, 'responsive and response-able relationalities' can be developed through studio practices.

The voices within this collection of perspectives on dance and somatic practices affirm that touch, improvisation, contact and CI are expansive sites in which to work. Though CI techniques can also appear to be quite a specialized practice within dance, how teachers and scholars approach dissemination of its story within academic and research contexts can help nudge this movement idea, in its 42 nd year of practice, further into the limelight.

Greater public exposure of any phenomenon risks its commodification and standardization, and the same may be said for CI. A culture of practice, a desire for flow, or a fundamental set of expectations about what $\mathrm{CI}$ is can create an unspoken set of agreements, which normalize practice and close the form. Normalizing suggests an answer, an essence, or core, creates a centre and a periphery, and risks losing the spirit of curiosity in Chung's description of CI as 'exploration of kinaesthetic possibilities'. Withness, and-ness looks at these practices not as a centre or periphery but as a field of potentiality, with differences to be acknowledged. The challenge for emerging discourses on contact [and] improvisation, in these circumstances, is to approach difference, as Paxton says, 'in an non-wimpy way' (Paxton in Cvejic and Laberenz 2013).

Contact cannot be resolved in (homeo)stasis. As it shifts, it dances (the two partners) from and in the in-between. (Williams 1996: 25) 
We hope that this dialogue, these articulations, might shift how we dance and how we think through our dances, so that these dances can continue to shift us.

$$
==
$$

\section{Acknowledgements}

This issue would not be possible without the expert coordination of JDSP's editorial assistant Emma Meehan, and the extended team of peer reviewers who offered generous feedback to support the development of these articles. We are grateful for the guidance of Ric Allsopp, Karen Nelson, Ruth Pethybridge and Daniel Metcalf who helped curate activities of Contact Festival Dartington Conferences 2013 and 2014, as well as to Richard Sarco-Thomas, co-organizer of CFD. We would also like to thank all the writers who responded to the call for contributions on CI praxis and enabled this first special issue on contact [and] improvisation to feature such a diversity of perspectives. 


\section{References}

Anon. (1982), 'Definitions of Contact Improvisation from Past CQs', Contact Quarterly, Winter, p. 59. Accessed 24th Jan 2013.

(n.d.), 'About Contact Improvisation (CI)', Contact Quarterly,

http://www.contactquarterly.com/contact-improvisation/about/cq_ciAbout.php.

Accessed 20th January 2013.

Brennan, T. (2004) The Transmission of Affect, Ithaca: Cornell University

Press.

Cvejic, B. and Laberenz, L. (2013), ‘...in a non-wimpy way / steve paxton’, http://vimeo.com/76095626. Accessed 2 April 2014.

Deitch-Dey, M. (1998), 'Change through exchange: Contact Improvisation’, M.Phil.

thesis, Dartington: University of Plymouth.

https://www.academia.edu/8310680/Change_Through_Exchange_Contact_Improvisation Accessed 10 Sept. 2014.

Guattari, Felix (2000), The Three Ecologies (trans. Ian Pindar and Paul Sutton), London: Continuum.

Hall, S. and Du Gay, P. (1996), Questions of Cultural Identity, London: Sage Publications.

Nancy, J. (2000), Being singular plural, Stanford University Press, Stanford, California. Novack, Cynthia (1990), Sharing the Dance: Contact Improvisation and American Culture, Madison: University of Wisconsin Press. 
Paxton, S. (1975), 'Contact Improvisation', The Drama Review: TDR, 19:1, pp. 40-42.

Sarco-Thomas, M. (2010), Twig Dances: Improvisation Performance as a Practice of Ecology, PhD thesis. Dartington: University of Plymouth.

Sarco-Thomas, M. and Dey, M. (2014), 'Framing the gap: Contact [and] Improvisation', Journal of Dance and Somatic Practices, 6:2, pp. 3-x.

Sennett, R. (2008), The Craftsman, London: Allen Lane.

Stark Smith, N. (2012), 'Talk through', The Global Underscore, Somatics and

Technology Conference, Sussex: University of Chichester, 23 June.

Williams, D. (1996), 'Working (in) the in-between: Contact Improvisation as an ethical practice', Writings on Dance, 15, pp. 22-37.

\section{Contributor details}

Dr Malaika Sarco-Thomas curates, practices, performs and researches contact and improvisation. With Richard Sarco-Thomas she co-organizes Contact Festival Dartington and Conference, an annual platform for the development and exchange of CI practice, and co-teaches 'Aikicontact' or Aikido and CI principles in movement. Together since 2007 they have organized weekly contact jams at Dartington College of Arts in Devon and now Falmouth University in Cornwall, where Malaika is a senior lecturer and course coordinator for B.A. Dance \& Choreography in the Academy of Music and Theatre Arts. In November 2014 she will join the School of Performing Arts at the University of Malta as a lecturer in Dance Studies. 
Misri Dey is a contemporary theatre practitioner and senior lecturer in Theatre at Falmouth University. She has had an on-going engagement with CI through earlier training and practice-based research, working with it in the UK, the USA and India and culminating in writing up an M.Phil thesis in 1998 called 'Change Through Exchange: Contact Improvisation'. Her recent focus as practitioner and researcher is in solo devised performance, having made four solo performances for radio and theatre exploring mixed ethnic identity and what this can perform. Her current work includes an in-depth series of interviews with highly experienced national and international solo devisor/performers, currently being written up as a Ph.D and developed for publication. She also founded and now co-coordinates the Solo Contemporary Performance Forum (SCPF) with Ria Hartley, originally at Dartington College of Arts 2004-2008 and now operating out of Bristol and Falmouth. It supports solo practitioners through organising and curating laboratory, residency and performance platforms. The SCPF is about to launch a website in Jan 2015.

\section{Contact:}

E-mail: bailalaika@hotmail.com

E-mail: misri.dey@falmouth.ac.uk

Notes

1 Curated by Karen Nelson, Misri Dey, Malaika Sarco-Thomas and Ric Allsopp.

${ }_{2}$ Curated by Ruth Pethybridge, Malaika Sarco-Thomas, Daniel Metcalf and Ric Allsopp. 